\title{
Quick-Erect Stopping System for Radiation Protection and Mine Rescue in Small-scale Mining
}

\author{
Jörg Dehnert ${ }^{1}$ (1) $\cdot$ Jens Stopp ${ }^{2} \cdot$ Peter Windisch $^{3} \cdot$ Bernd Schönherrt $^{3}$
}

Received: 12 November 2018 / Accepted: 8 July 2020 / Published online: 23 July 2020

(C) The Author(s) 2020, corrected publication 2020

\begin{abstract}
The Quick-Erect Stopping System (QESS) offers a new way of reducing the radon exposures of miners in Germany, especially during remediation work in old mines. The QESS is a light-weight, modular, and reusable construction kit of interlocking telescopic aluminum tubes, radon-proof foil, and expanding foam. It is designed to seal off radon-rich parts of galleries within only a few minutes. Originally, the QESS was developed to protect miners against radon exposures. Then, the QESS found the attention of several mine rescue teams at a German mining conference. The Student Mine Rescue of the Technical University Bergakademie Freiberg and the Wismut Mine Rescue carried out first mine rescue drills in Freiberg and Schlema. Additionally, a mine rescue drill was carried out by the Front Range Mine Rescue in the Edgar Experimental Mine of the Colorado School of Mines. These drills helped to improve the system and highlighted its potential for mine rescue operations. Now, the QESS is wellsuited for small-scale mining. The QESS can be used to seal off galleries in only a few minutes to both protect miners from radon exposures and to support mine rescue operations. Moreover, the QESS was also successfully used in ventilation experiments.
\end{abstract}

Keywords Radon $\cdot$ Radiation protection $\cdot$ Ventilation $\cdot$ Stopping $\cdot$ Mine rescue

\section{Introduction}

Mining in the Ore Mountains (Erzgebirge) and Vogtland mountains began in the twelfth century and continues to this very day. Both mountains are low-mountain ranges in the East German state of Saxony. Numerous villages and small towns display a rich heritage of historically valuable buildings. Mining itself has left numerous galleries and shafts that cause occasional surface damage. To protect people, buildings and infrastructure, in an average year around 250 miners from eight companies, are permanently engaged in remediation work at up to 40 smaller and frequently changing construction sites.

The original online version of this article was revised to correct processing errors of Figs. 4 and 5.

Jörg Dehnert

joerg.dehnert@smul.sachsen.de

1 Saxon State Office for Environment, Agriculture and Geology, Pillnitzer Platz 3, 01326 Dresden, Germany

2 Aluminiumbau und Verwaltungs GmbH Stopp, Am Gerichtsberg 15, 08289 Schneeberg, Germany

3 Bergsicherung Schneeberg GmbH \& Co KG, Kobaltstr. 42, 08289 Schneeberg, Germany
Moreover, potential dangers are eliminated ensuring safety at the surface above old galleries. Additionally, many gallery systems serve as drainage adits for mining areas. They must be kept functional to drain away mine water into rivers. Examples are the Markus Semmler gallery in Schneeberg (with a length of $29.4 \mathrm{~km}$, i.e., 18.3 miles), the Rothschönberger gallery near Freiberg (with a length of $28.9 \mathrm{~km}$, i.e., 18 miles), or the Tiefe Elbstolln gallery in Freital (with a length of $5.7 \mathrm{~km}$, i.e., 3.5 miles). The Markus Semmler gallery was built between 1503 and 1841 and is currently being reconstructed.

The high radon potential in the Saxon Erzgebirge and Vogtland is significant for radiation protection of miners during remediation work. It is not unusual to find radon activity concentrations of $100,000 \mathrm{~Bq} \mathrm{~m}^{-3}$ in mine air currents under natural ventilation. Figure 1 displays the course of the radon activity concentration in the gallery Querschlag 68 in Schneeberg. The radon activity concentration varied between 32,000 and $85,000 \mathrm{~Bq} \mathrm{~m}^{-3}$ within a period of 7 days [1]. The reference value for the average annual radon activity concentration in the air at workplaces is $300 \mathrm{~Bq} \mathrm{~m}^{-3}$ under the German Radiation Protection Act [2]. The German Radiation Protection Ordinance assumes that an exposure of $0.32 \mathrm{MBqh} \mathrm{m}^{-3}$ is equivalent to an effective dose of $1 \mathrm{mSv}$, when the equilibrium factor between radon and its short-live decay products is 0.4 [3]. Therefore, if a miner works $2000 \mathrm{~h}$ annually in mine air 
Fig. 1 Course of the radon activity concentration in the gallery Querschlag 68 in Schneeberg [1]

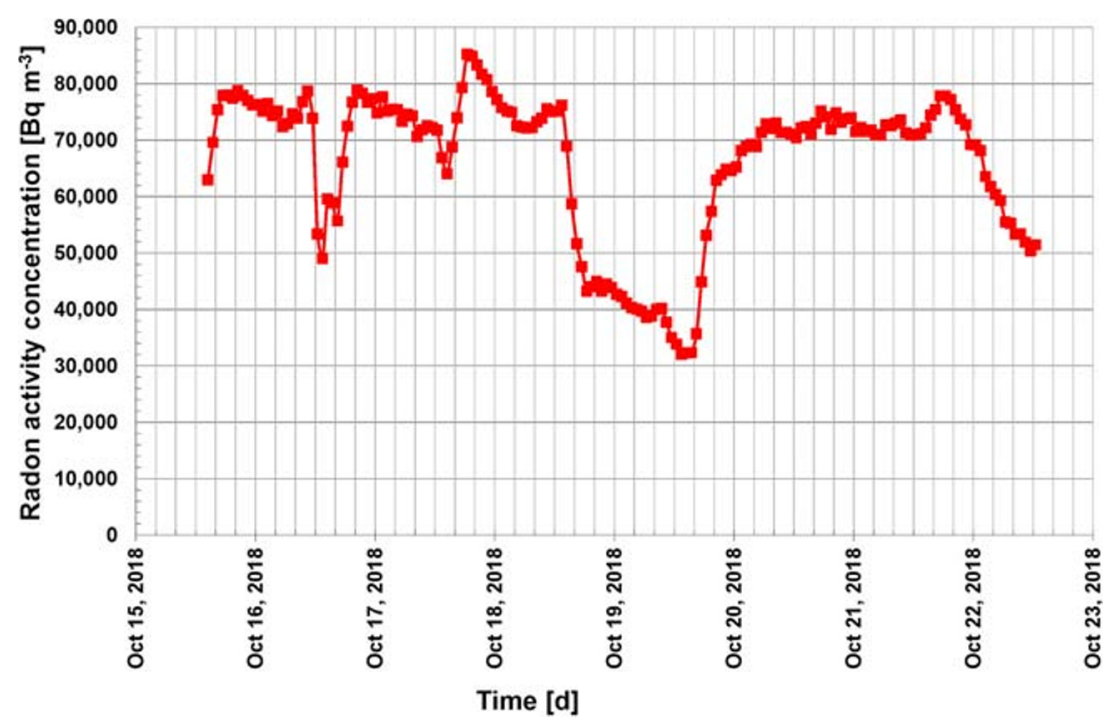

with a radon activity concentration of $3000 \mathrm{~Bq} \mathrm{~m}^{-3}$, this leads to an annual effective dose of $20 \mathrm{mSv}$. This dose is the annual limit, which must not be exceeded.

Therefore, old mining sites pose a significant challenge when it comes to protecting miners against radon exposures. The most important radiation protection measures are the ventilation with mobile mine fans and pipes, the temporary sealing off of galleries with the help of mine stoppings, and the rotation of miners after working at construction sites with high radon activity concentrations $[4,5]$.

In contrast to active mining, mobile mine fans are used at smaller and frequently changing construction sites during remediation work in old mines. These fans are often powered by diesel generators and are of limited effect. Therefore, it happens from time to time that strong radon-containing mine air flows from galleries into construction sites. Hence, it is important to seal off such galleries with stoppings.

In Saxony, miners at old mining sites usually erect stoppings for remediation work with the help of wood, foil, and expanding foam. Figure 2 shows a conventional wood

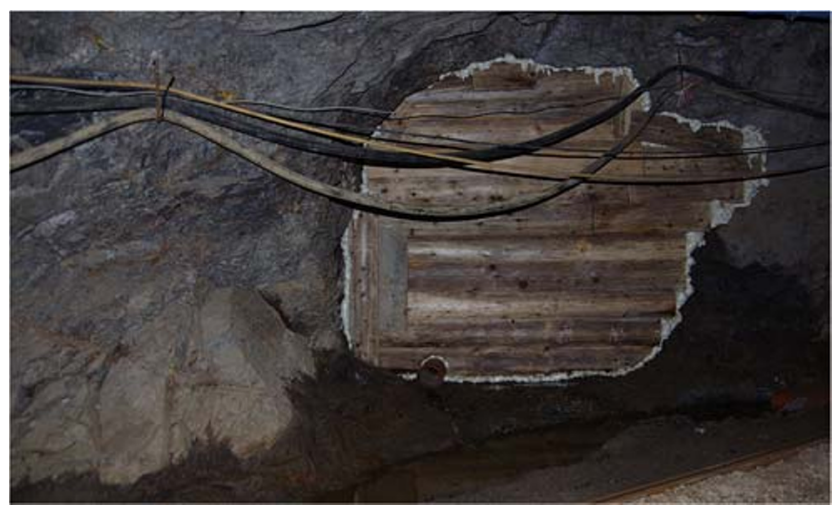

Fig. 2 Conventional stopping made of wood in the gallerie Querschlag 24 in Schneeberg stopping in the gallery Querschlag 24 in Schneeberg. Erecting such stoppings is time-consuming. On average, two miners need $4 \mathrm{~h}$ to build one stopping. First, miners need to carry by hand material and tools from the mine opening through narrow and twisted galleries to the construction site. The distance they have to cover can amount to several hundred meters. To get all the material to the construction site, miners must make their way multiple times. Then, they have to construct the stoppings to a perfect fit with the wood on site. To do so, they have to measure the mine openings meticulously. In the end, the stoppings are sealed with expanding foam. Stoppings need to be dismantled before and re-erected after all blasting operations. As a result, miners have to endure radoncontaining mine air for many hours.

Miners carrying out remediation work at old mining sites in Saxony are monitored with personal radon dosimetry [6]. Figure 3 shows the distribution of miners' effective annual doses in 2017. The effective doses are rather high compared to employees in industry and medicine, although head miners responsible for radiation protection are very dedicated, and companies invest significant resources into radiation protection measures (Fig. 4).

To lower the effective doses of miners in underground remediation work in Saxon old mines, the Quick-Erect Stopping System (QESS) was developed. With the QESS, mine openings of any width can be sealed off within a few minutes.

The QESS was presented at the German mining conference FreiBERGbau in Freiberg and attracted the attention of several mine rescue teams [7]. As a result, the Student Mine Rescue of the Technical University Bergakademie Freiberg, the Wismut Mine Rescue of Aue, and the Front Range Mine Rescue of Idaho Springs, Colorado, carried out mine rescue drills using the QESS. Based on the recorded experiences during these drills, the system was improved. At present, the QESS is well-suited for small-scale mining. The QESS can be 
Fig. 3 Distribution of the effective annual doses of miners carrying out repair works at old mining sites in Saxony 2017

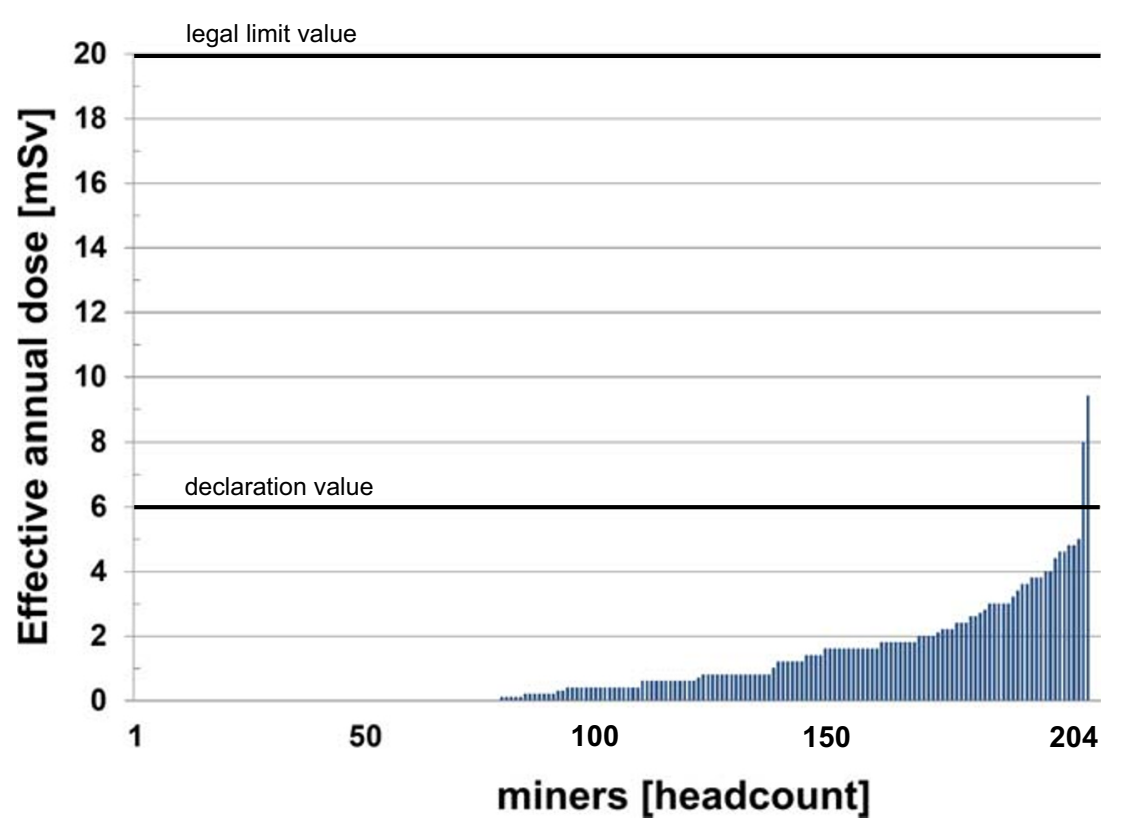

used to seal off galleries in mines in only a few minutes protecting miners from radon exposures and supporting mine rescue operations. Moreover, the QESS was also successfully used in ventilation experiments.

\section{The Quick-Erect Stopping System}

The QESS is a light-weight, modular, and reusable construction kit consisting of interlocking telescopic aluminum tubes, radon-proof foil, and expanding foam able to seal off radonrich parts of galleries of any width within only a few minutes. The QESS comes boxed for transport over ground and includes two bags for transportation underground. The QESS can be extended by more kits [8].

A construction kit contains 15 two-piece, extendable telescopic tubes in four different lengths, which are color-coded with reflecting foil (red, green, yellow, and blue). All tubes

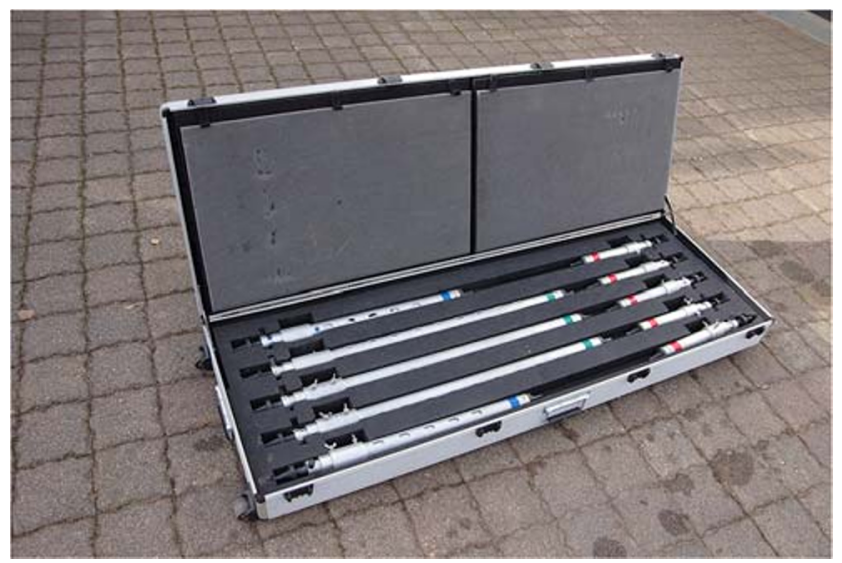

Fig. 4 Quick-Erect Stopping System (QESS) in its transportation box have regularly placed slots from top to bottom on both sides. The longest tubes have also a single slot at the front. The tubes are equipped with tips made of hard plastic at both ends. The tube tips can be inserted into the slots of other tubes. One of the two tips of a tube is equipped with a spring. Therefore, the telescopic tubes can be pulled out and stretched to brace radon-proof foil in a gallery. The tubes have two screws to lock the stretched parts. The telescopic tubes can either be inserted in other telescopic tubes or braced independently. They do not have to assume a radial form but can be braced freely adapting to any imaginable form of a mine opening. If necessary, the telescopic tubes can be extended out of the cross section to brace the foil in front of or behind the cross section. Under conditions of high pressure in the gallery, it is possible to support the QESS from the front with telescopic tubes against the floor, walls and ceiling by using the front openings in the tubes. Finally, the erected structure is sealed with expanding foam (Fig. 5).

The radon-proof foil used is $50 \mathrm{~m}(164 \mathrm{ft})$ long and stored on a roll of $1.5 \mathrm{~m}(5 \mathrm{ft})$ width. The foil is equipped with adhesive strips on both sides so that sheets of foil can be attached to one another without additional equipment. For quick assembly of the QESS, it is recommended to preprepare several 'patches' of different sizes for respective mine openings. Such patches could have the size of, for example, $3 \mathrm{~m} \times 3 \mathrm{~m}(10 \mathrm{ft} \times 10 \mathrm{ft}), 5 \mathrm{~m} \times 3 \mathrm{~m}(16 \mathrm{ft} \times 10 \mathrm{ft})$, and $8 \mathrm{~m} \times 5 \mathrm{~m}(26 \mathrm{ft} \times 16 \mathrm{ft})$.

The QESS construction kit comes in a robust box made of metal-lined foam for transport over ground (Fig. 4). One boxed QESS construction kit can be carried by two miners to a vehicle in one go and then driven to the mine opening for use. 


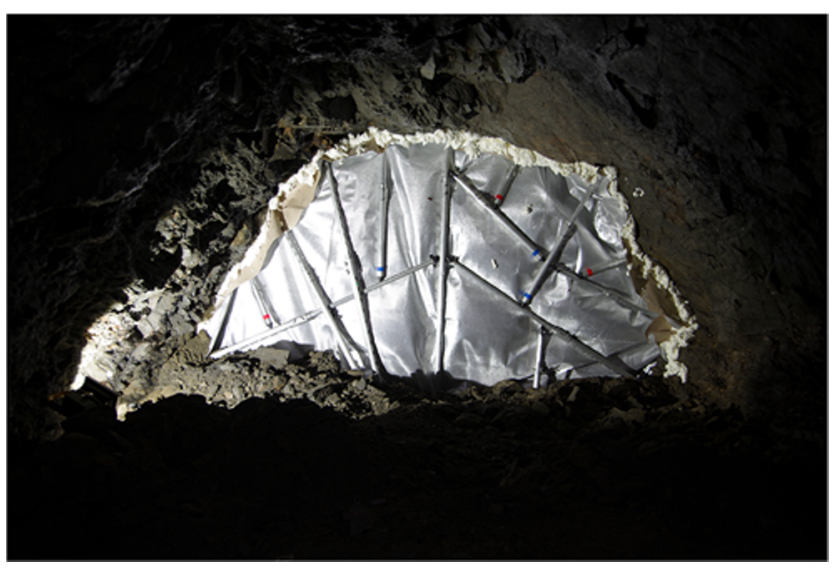

Fig. 5 Quick-Erect Stopping System (QESS) in the gallery Querschlag 68 in Schneeberg

The two bags for underground transportation are robust and have three carrying handles: one in the front, one in the middle, and one in the back. The bags are especially designed for horizontal and vertical transport in narrow galleries. Two miners can carry both bags to the assembly site in only one go.

It is possible to turn the QESS into a mine door. Therefore, a zipper is affixed to the foil and the foil is cut, while the zipper is opened.

Setting up the QESS takes two miners 15 to $30 \mathrm{~min}$. The QESS can be dismantled in less than $5 \mathrm{~min}$. It is reusable except for the foil and the foam and can be re-erected after a blasting operation at the same location, for instance, or reused at another location. To erect the QESS, no tools and electricity are required. There is no need to measure the gallery to be sealed off. A guesstimate of width and height is sufficient to decide which of the prepared patches match the respective opening. Moreover, the reflecting foil of the color-coding can be seen well in the light of miners' lamps. In sum, the QESS has the following features:

- modular construction kit;

- fits into any cross section;

- quick setup and dismantling;

- reusable (except for foil and foam);

- light weight;

- fast and easy transport by hand;

- no need to measure the gallery to be sealed;

- setup without tools and electricity;

- with radon-proof foil;

- can be turned into a mine door by affix a zipper;

- extendable by more kits.

The QESS protects miners from radon, smoke, and dust. In comparison to conventional stoppings made of wood and foil, the QESS reduces the radon exposures of miners due to its significantly shorter assembly time. The QESS is protected by a patent [9].

\section{Radiation Protection}

The QESS was developed to protect miners against radon exposures during remediation work at old mining sites; it was used, for instance, while reconstructing the historical Markus Semmler gallery in Schneeberg [10]. Figure 6 shows the construction site in the Markus Semmler gallery at the section Fleischer Morgengang. The mobile construction site moved slowly through the gallery for a few meters every day (Fig. 7). The construction site was ventilated by a pushing mine fan in the shaft Beustschacht and a pulling mine fan in the shaft Adam Heber Schacht. Just in front of the mobile construction site, the crosscut Querschlag 60 erected by the Wismut GmbH joined the Markus Semmler gallery. The crosscut Querschlag 60 had caved in. Nevertheless, strong radon-containing mine air currents funneled through the cave-in into the Markus Semmler gallery due to low air pressure.

To protect miners in the Markus Semmler gallery when passing the mouth of the crosscut, the QESS was erected in the crosscut Querschlag 60. Conditions for its erection were tough. In the Markus Semmler gallery, the water level was at

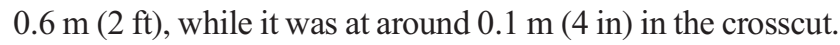
Under these difficult conditions, setting up the QESS in the water took two miners an hour, which included the sealing with expanding foam. Stoppings are usually not absolutely tight. A day after its erection, miners sealed the QESS with foam a second time to improve the tightness of the stopping. This established effective radiation protection for the miners in the area of the mouth of the crosscut Querschlag 60 at the Markus Semmler gallery (Fig. 8). The construction site could now move forward into the mouth of the crosscut.

The radon activity concentration was monitored at four measuring points with radon monitors Radon Scout by Sarad GmbH. Figure 9 shows the course of the radon activity concentration for three of the four measuring points in the Markus Semmler gallery. The points were located (1) $520 \mathrm{~m}$

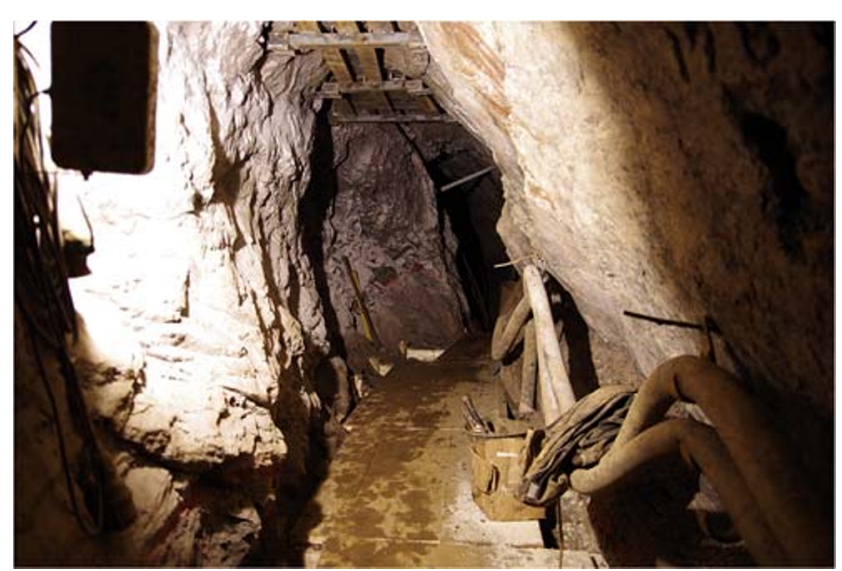

Fig. 6 Reconstruction of the Markus Semmler gallery at the section Fleischer Morgengang in Schneeberg 


\section{To shaft Adam Heber Schacht}

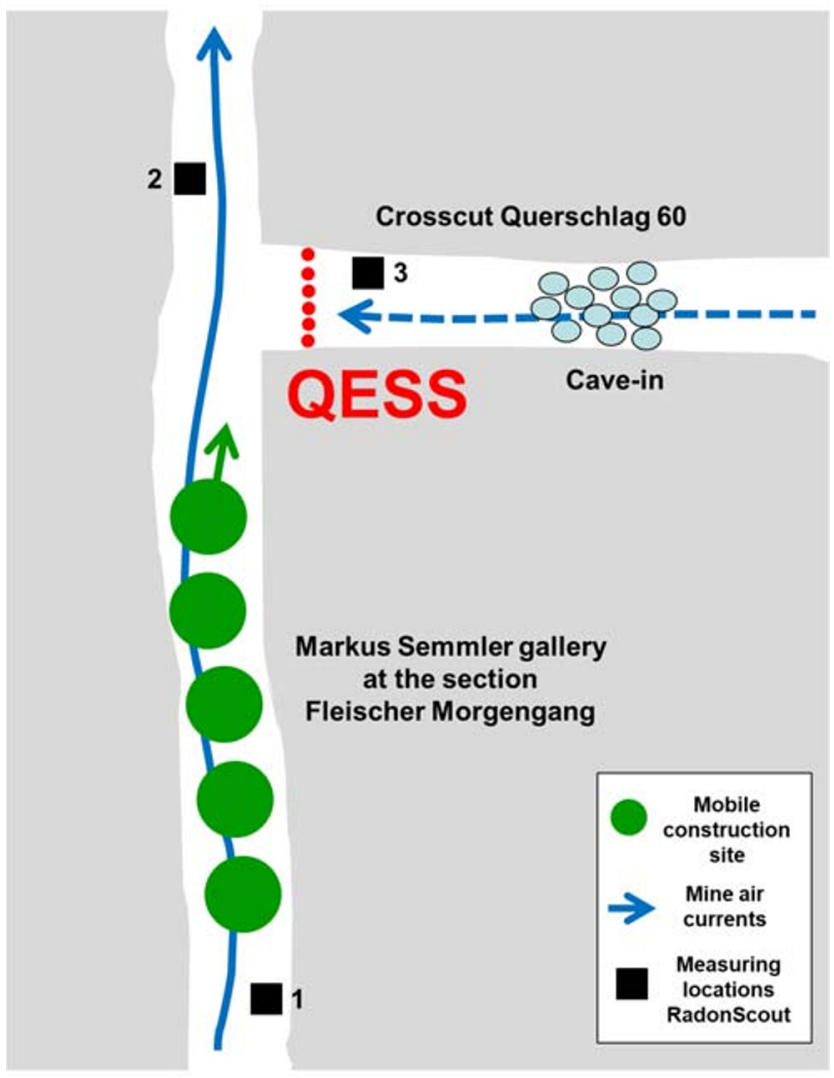

From shaft Beustschacht

Fig. 7 Map of the construction site in the Markus Semmler gallery at the section Fleischer Morgengang in Schneeberg

in front of the mouth of crosscut Querschlag 60, (2) some meters after the mouth of the crosscut, and (3) in the crosscut behind the QESS. The fourth measurement point was at a nonrepresentative location in front of the QESS and will therefore not be discussed in this article. Comparatively low and constant radon activity concentrations from $200 \mathrm{~Bq} \mathrm{~m}^{-3}$ at

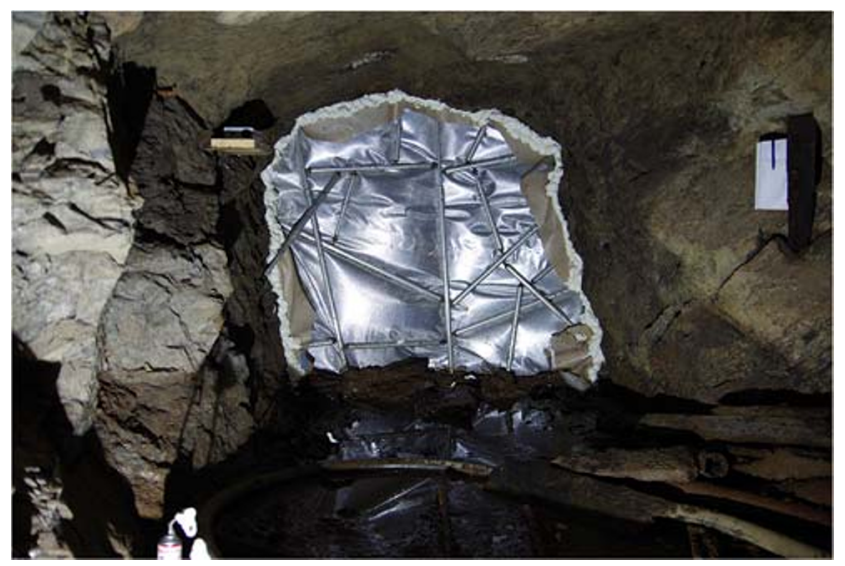

Fig. 8 Quick-Erect Stopping System (QESS) in the crosscut Querschlag 60 to protect the construction site in the Markus Semmler gallery at the section Fleischer Morgengang in Schneeberg measuring point (1) up to $1500 \mathrm{~Bq} \mathrm{~m}^{-3}$ at measuring point (2) were detected in the well-ventilated Markus Semmler gallery. In the crosscut Querschlag 60, the radon activity concentration increased from about $13,000 \mathrm{~Bq} \mathrm{~m}^{-3}$ to a new level of $25,000 \mathrm{~Bq} \mathrm{~m}^{-3}$ to up to $40,000 \mathrm{~Bq} \mathrm{~m}^{-3}$, after the QESS was erected.

Later, it was decided to turn the caved-in crosscut Querschlag 60 into a storage place for mud and rocks. Hence, the QESS was dismantled. After dismantling the QESS, a radon activity concentration of $11,000 \mathrm{~Bq} \mathrm{~m}^{-3}$ established itself in the crosscut. A new stopping made from wood and foil was erected in front of the caved-in rocks, and special ventilation with mine fan and pipes was laid from the Markus Semmler gallery into the crosscut to ventilate the new workplace of the miners. The effects of the new stopping and the ventilation starting in January 2019 are not included in Fig. 9.

This example shows that the QESS with its short assembly time can protect miners fast and efficiently from radon exposure during remediation work at old mining sites. It can be set up quickly even in difficult conditions, like water or confined space. When plans change, the QESS can be dismantled without much effort and re-erected at another location.

\section{Ventilation Experiments}

The QESS can also be used for experiments in order to optimize ventilation in mines. QESSs are set up one after the other or simultaneously at different locations in the mine to channel mine air currents. The stoppings' effect on mine air currents and on radon activity concentrations is measured. When the ventilation system is optimized, the QESS can either be left in place or replaced by conventional stoppings made of wood. That way, optimal ventilation paths in a mine can be established very quickly and with comparatively little effort.

Such a ventilation experiment with the QESS was conducted in the visitor mine Frisch Glück Glöckl in Johanngeorgenstadt [11]. The visitor mine belongs to the former Wismut mine Objekt 01. Here, 3770 tons of uranium was mined between 1946 and 1958.

The visitor mine has two parallel galleries, the gallery Silberstrecke with a cross-section of $0.8 \mathrm{~m} \times 1.60 \mathrm{~m}(2.6 \mathrm{ft} \times$ $5.2 \mathrm{ft}$ ), and the Wismut gallery with a cross-section of $2.60 \mathrm{~m} \times 2.20 \mathrm{~m}(8.5 \mathrm{ft} \times 7.2 \mathrm{ft})$. Both galleries are connected by a crosscut and deeper in the mine by a bypass and a staple shaft. Figure 10 shows the layout of the visitor mine's forward area.

The radon potential in the mine is high. A mine fan was set up in the mine near the crosscut. The mine door in the crosscut was closed, and the mine door in the Wismut gallery was opened (ventilation regime A). The mine fan pulled fresh mine air from the mine opening through the gallery 
Fig. 9 Course of the radon activity concentration at two measuring points in the Markus Semmler gallery before and after the mouth of crosscut Querschlag 60 and at an additional measuring point in the crosscut 60 with and without the Quick-Erect Stopping System (QESS)

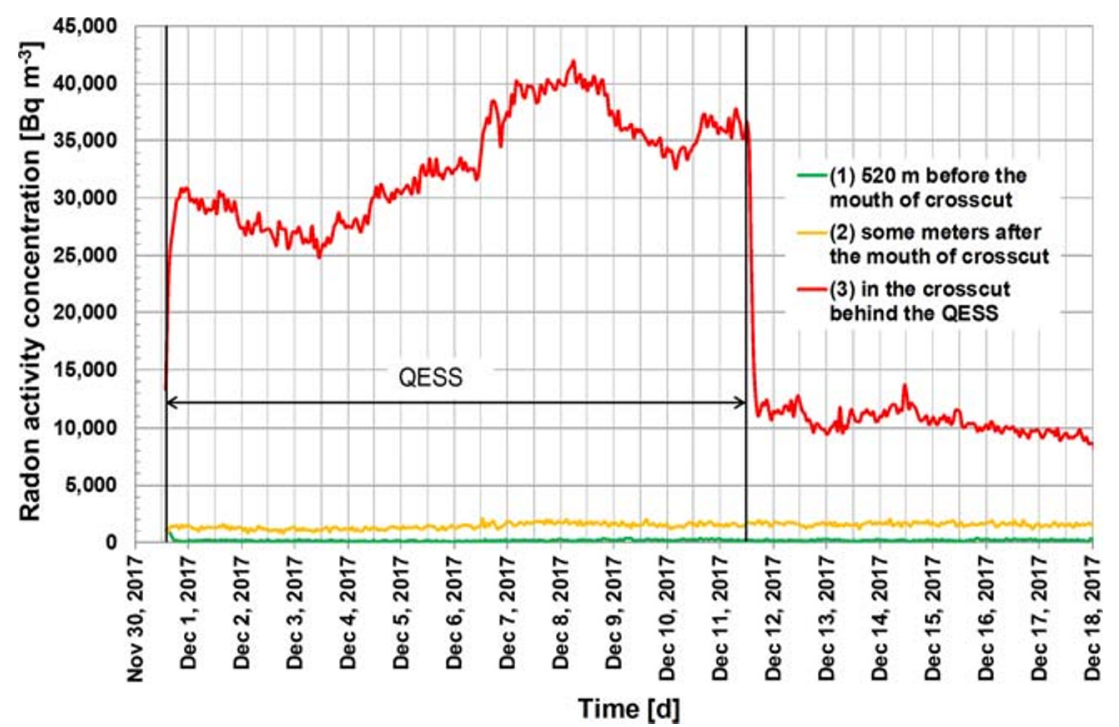

Silberstrecke and pushed the air towards bypass and staple shaft. Both mine guides are monitored with radon personal dosimetry. In 2014 and 2015, the mine guides' highest effective doses were $14.6 \mathrm{mSv}$ and $11 \mathrm{mSv}$, respectively. The effective doses of the guides were under the limit of $20 \mathrm{mSv}$ according to the German Radiation Protection Act but still

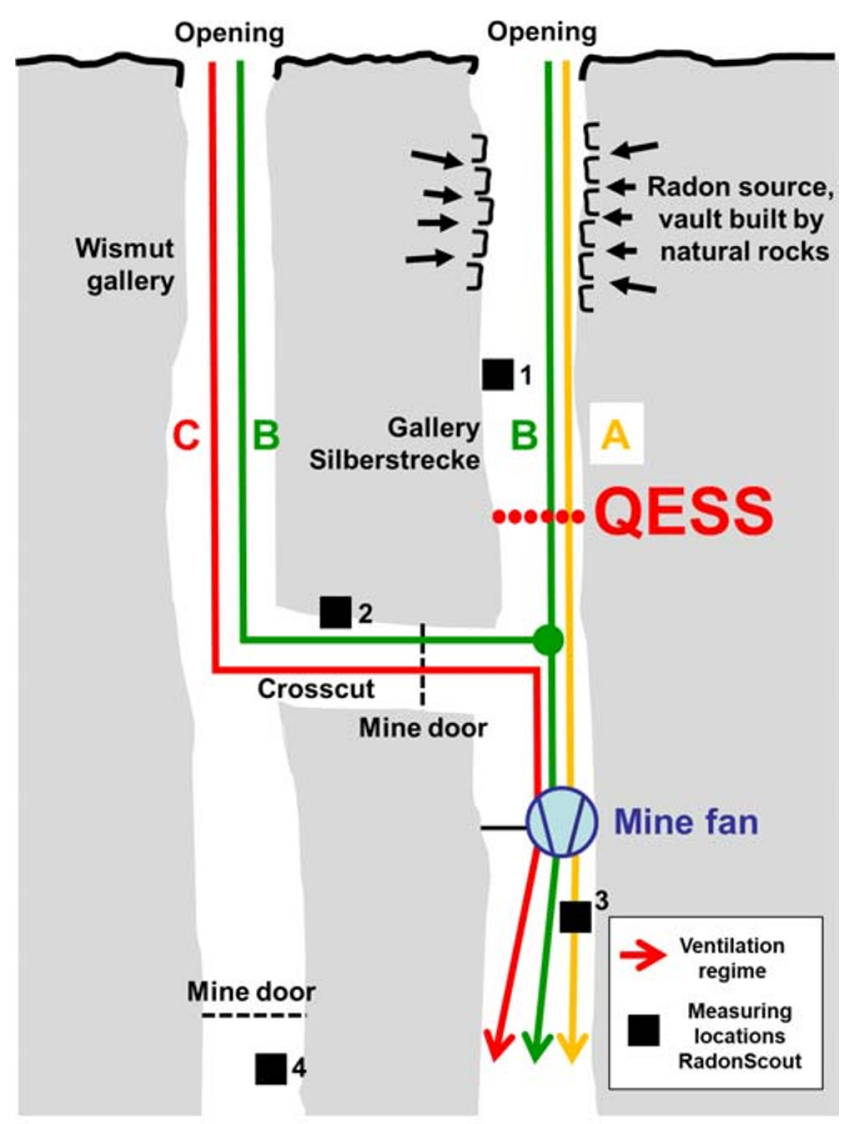

Fig. 10 Layout of the visitor mine's forward area with ventilation regime $\mathrm{A}, \mathrm{B}$, and $\mathrm{C}$, and measuring points (1) to (4) [11] unusually high [2]. Following the basic international radiation protection principle ALARA (as low as reasonably achievable), these doses were meant to be reduced.

The radon activity concentration in the visitor mine was investigated using the radon monitor AlphaGUARD PQ2000 PRO by Saphymo GmbH. It was established that the fresh mine air currents displayed a radon activity concentration of $3000 \mathrm{~Bq} \mathrm{~m}^{-3}$ only a few meters after the mine opening. The radon activity concentration increased up to $5000 \mathrm{~Bq} \mathrm{~m}^{-3}$ at the mine fan. The reason for this was the vault built of natural rocks behind the mine opening. The fan concurrently pulled in both fresh mine air currents through the mine opening and strong radon-containing mine air currents through the open joints in the vault built of natural rocks. As a result of this finding, the ventilation regime was altered by the association Bergknappschaft Johanngeorgenstadt, the visitor mine's operator. The mine door in the crosscut was opened, and the mine door in the Wismut gallery was closed. Now, the mine air currents funneled through the two-parallel galleries Silberstrecke and Wismut gallery at the same time (ventilation regime B). As a result, the mine guides' effective dose could be cut in half to $4.8 \mathrm{mSv}$ in 2016 .

The question arose of whether it would be possible to further reduce the mine guides' effective dose. The idea was to set up a mine door in the gallery Silberstrecke to funnel the mine air currents through the parallel Wismut gallery only (ventilation regime $\mathrm{C}$ ). The vault built of natural rocks would be eliminated as a source of radon. For this purpose, a ventilation experiment was conducted. The gallery Silberstrecke was sealed off with the QESS (Fig. 11). The course of the radon activity concentration was measured with radon monitors Radon Scout by Sarad $\mathrm{GmbH}$ at five measuring points in the visitor mine. The measuring interval was 1 . Figure 12 shows the course of the radon activity concentration for 1 week without the QESS and for another week with the QESS at the 


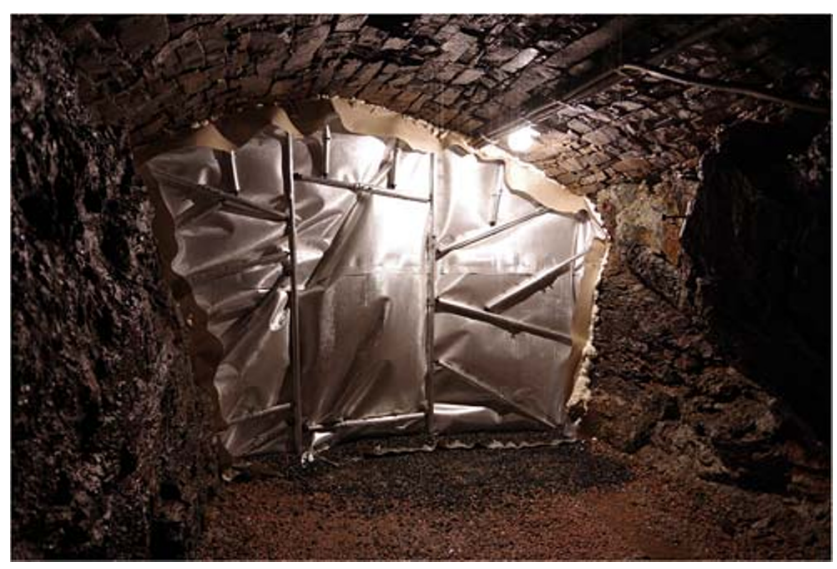

Fig. 11 The gallery Silberstrecke with Quick-Erect Stopping System (QESS) set up in the visitor mine [11]

five measuring points: (1) Gallery Silberstrecke, (2) Crosscut, (3) Pushing side of the mine fan, (4) Pikhammer, and (5) Bypass. The mine fan's operating hours were very short and ranged from 2 to $7 \mathrm{~h}$ per day during the 2-week period of the ventilation experiment. The fan was not used on all days.

It was found that after the QESS was set up, the radon activity concentration in the gallery Silberstrecke increased significantly up to $50,000 \mathrm{~Bq} \mathrm{~m}^{-3}$. The QESS had sealed air-tight the gallery Silberstrecke on the ground, walls, and ceiling. Nevertheless, the radon activity concentration at the pushing side of the mine fan remained surprisingly unaffected by the QESS. The next finding was that radon-containing mine air currents funneled through the natural rocks above the ceiling and the QESS through the gallery Silberstrecke to the mine fan. Sealing the gallery Silberstrecke completely by using a stopping was impossible due to this very nature of its ceiling. The radon activity concentration at the bypass was influenced by the staple shaft and was also independent of the QESS. Therefore, a stopping could not improve the situation. The ventilation regime B was maintained.

The experiment shows that the QESS can be used for ventilation experiments with little time and effort. Carpentering a stopping was not necessary. The QESS was braced against the surrounding rock, stood very stable in the gallery, and withstood higher mine air pressures, caused by the near mine fan.

\section{Mine Rescue}

The QESS was presented at the German mining conference FreiBERGbau in Freiberg [7]. There, several mine rescue teams discussed the question of whether the QESSoriginally developed for the radiation protection of miners in remediation work at old mining sites - could be used in mine rescue operations in order to set up a ventilation dam or a ventilation pre-dam. A mine rescue team consists of four mine rescuers and a team leader. One such team would certainly be able to quickly bring the QESS with its two carrier bags to the required site and erect it within a few minutes. Respectively, two mine rescuers would carry one bag. At the operation site, the telescopic tubes are placed on the ground and arranged in groups by their color coding. The prepared patch of foil is unfolded on the ground, centrally aligned, and braced with the first telescopic tube between ground and ceiling in the center of the gallery by two mine rescuers. Subsequently, the mine rescuers in teams of two can brace at the same time both sides of the QESS with telescopic tubes, yet independently from one another. The teams call out colors to their team leader, who can hand the requested telescopic tubes to the teams very quickly due to the color coding of the tubes. If the rescue of individuals is expected, as a precaution, two telescopic tubes can initially be placed in parallel from each
Fig. 12 Course of the radon activity concentration at five measuring points in the visitor mine with and without the QuickErect Stopping System (QESS) in the gallery Silberstrecke [11]

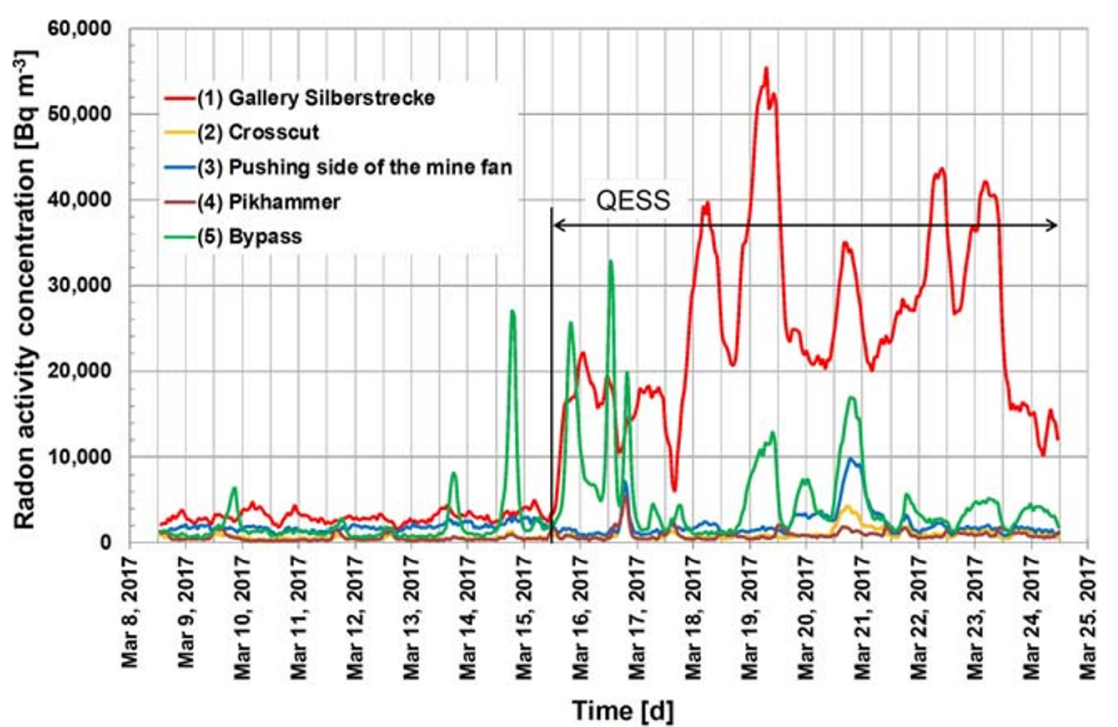




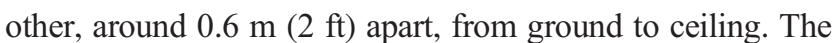
telescopic tubes are braced crossways with two additional telescopic tubes at the top and bottom and can be turned into a mine door later on. For this, if necessary, a self-sticking zipper is affixed to the foil, and the foil is cut while the zipper is opened. Now mine rescuers can advance to rescue individuals and close the QESS behind them like a door. Especially for mine rescue teams, it is of great advantage that neither tools nor electricity are necessary for setting up the QESS. The gallery itself does not need to be measured; a guesstimate of width and height is sufficient. The QESS can also be securely erected in a gallery filled with smoke. For this, the reflective color coding on the telescopic tubes is helpful, as it can easily be seen in the light of miners' lamps.

The Student Mine Rescue of the Technical University Bergakademie Freiberg tested the QESS in two mine rescue drills at the Teaching and Research Mine Reiche Zeche in Freiberg (Fig. 13). To simulate the physical stress of an actual operation, breathing apparatuses type BG-174 were worn. How the QESS works is mostly self-explanatory. Three teams (Red 17, Green 17, and Eckern 17) were formed after a short instruction session. One after another, the teams were given the task to set up the QESS $700 \mathrm{~m}$ $(0.4 \mathrm{mi})$ away from the shaft Reiche Zeche in the gallery section Wilhelm Stehender and to assess it in terms of its suitability for mine rescue operations. The cross section that was to be sealed off was around $4 \mathrm{~m}^{2}$ (43 sq. $\mathrm{ft}$ ). Figure 14 shows the QESS erected by the teams Red 17 (top), Green 17 (middle), and Eckern 17 (bottom). The assembly times were $20 \mathrm{~min}, 25 \mathrm{~min}$, and $20 \mathrm{~min}$, respectively. There was no sealing off of the QESS by expanding foam in the gallery. Team Green 17 was given the task to erect the QESS in a way that a door could be added later on by affixing a zipper to the foil. This accounts for the slightly longer assembly time. The QESS erected by the teams at

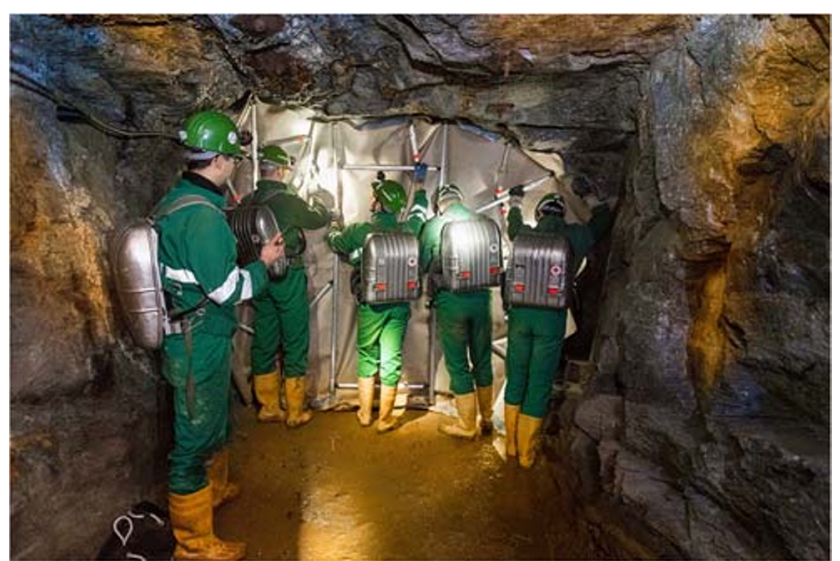

Fig. 13 Setup of the Quick-Erect Stopping System (QESS) by a troop of the Student Mine Rescue of the Technical University Mining Academy of Freiberg in the gallery section Wilhelm Stehender in the Teaching and Research Mine Reiche Zeche. Image: Detlev Müller/Technical University Bergakademie Freiberg
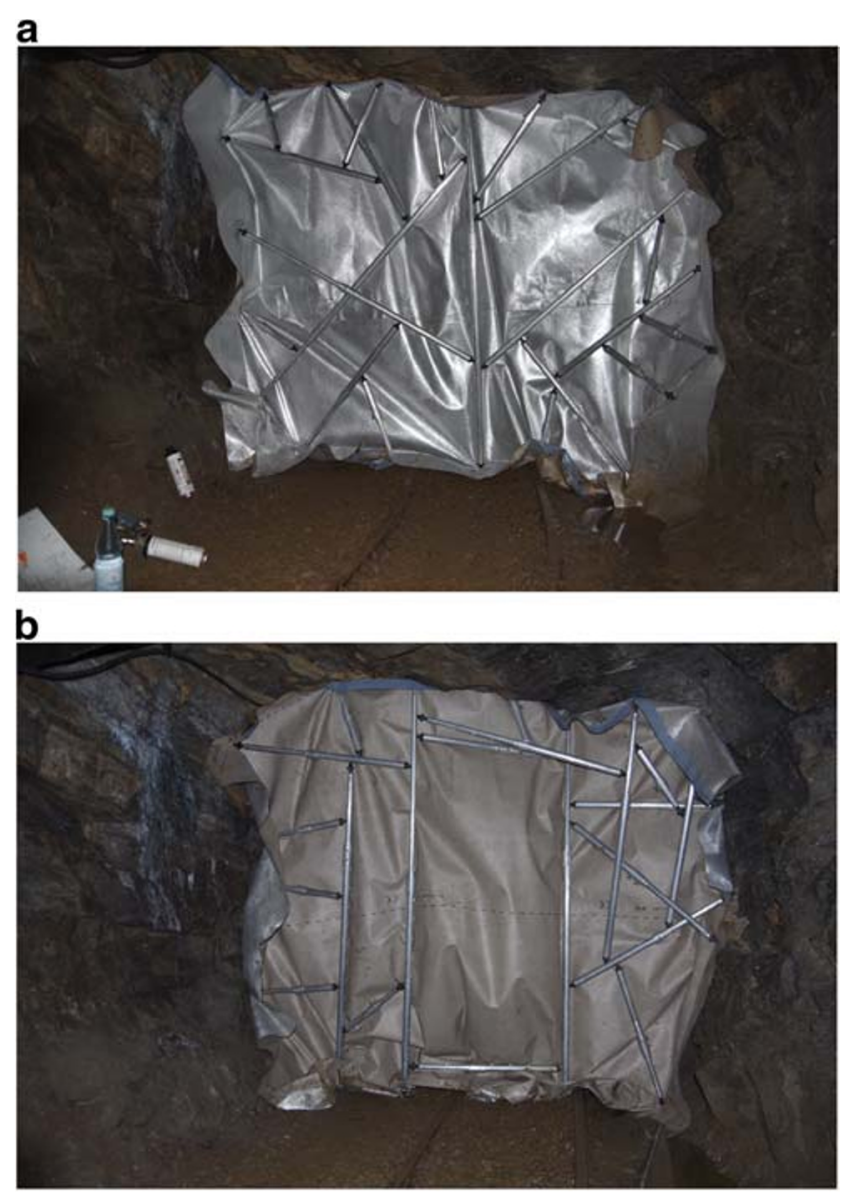

C

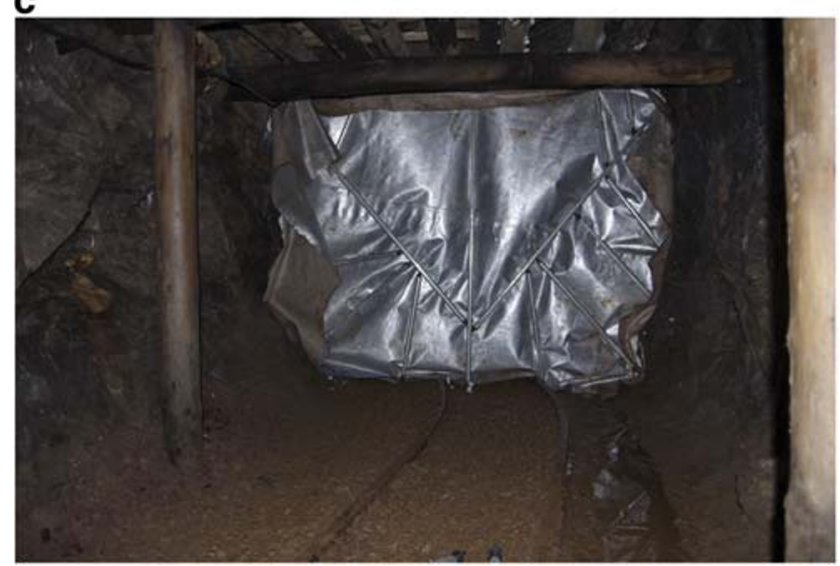

Fig. 14 Setup of the Quick-Erect Stopping System (QESS) by troops Red 17 (top), Green 17 (middle), and Eckern 17 (bottom) in the gallery section Wilhelm Stehender in the Teaching and Research Mine Reiche Zeche with assembly times of $20 \mathrm{~min}, 25 \mathrm{~min}$, and $20 \mathrm{~min}$ again

the same spot differ distinctly from one another. This demonstrates the system's versatility. All erected QESSvariants were solid. The inwardly curved foil shows the mine air pressure in the mine. All three teams did not have any pre-knowledge and worked with the QESS for the first time. It may be noted that team Eckern 17 mainly consisted of women. The Student Mine Rescue of the Technical 
University Bergakademie Freiberg made worthwhile suggestions for improving the QESS based on this drill.

These suggestions were implemented and a revised version of the QESS was developed. This improved version has features that should allow erecting it even faster under the tough conditions of a mine rescue operation. For example, the telescopic tubes now have small rubber handles that facilitate a faster and more powerful bracing, even in poor visibility. In addition, slot distances on both sides of the telescopic tubes were optimized.

A second mine rescue drill was conducted with this QESS by the Student Mine Rescue of the Technical University Bergakademie Freiberg in the gallery Reiche Zeche. The drill was observed by an experienced team leader of the Wismut Mine Rescue. This time, the three teams' assembly times were only $17 \mathrm{~min}, 11 \mathrm{~min}$, and $10 \mathrm{~min}$ respectively (Fig. 15). There was again no sealing off of the QESS in the gallery by expanding foam. This drill allowed to conclude that the QESS is suitable as a ventilation pre-dam for mine rescue operations. In case of a fire, the QESS can help to very quickly reduce the throughflow of mine air currents and thus the oxygen feed of the fire. The fire weakens, and time is won for additional rescue measures. Subsequent mine rescue drills by the Wismut Mine Rescue of Aue, Germany, and the Front Range Mine Rescue of Idaho Springs, Colorado, also generated positive feedback.

The QESS works well in small-scale mining. This raised the question of whether the QESS can also be used for larger mine openings. To investigate this question, the longest of the two-piece telescopic tubes were turned into three-pieced telescopic tubes, while the number of telescopic tubes in the set was increased. The setup method was adjusted. For example, short holes were drilled with a cordless drill into walls, ceilings, and the floor to insert and safely anchor the tips of the telescopic tubes. With this QESS version adapted to active mining, mine openings with a ceiling height of up to $4 \mathrm{~m}$ (13 ft) can be sealed off. Initial tests were carried out in the visitor mine Zinnkammern in Pöhla (Fig. 16) and in the salt mine Schachtanlage Asse II in Remlingen (Fig. 17). In both test runs, the QESS could be erected safely. It now has to be investigated whether and under what conditions the QESS can withstand greater physical pressure in mines. It may be necessary to increase the diameter of the telescopic tubes. The QESS would then get heavier and could no longer be carried by hand by two miners.

\section{Discussion}

The QESS was developed for the radiation protection of miners during remediation work in old mines in the Saxon Erzgebirge and Vogtland mountains. Here, construction sites are characterized by narrow and winding
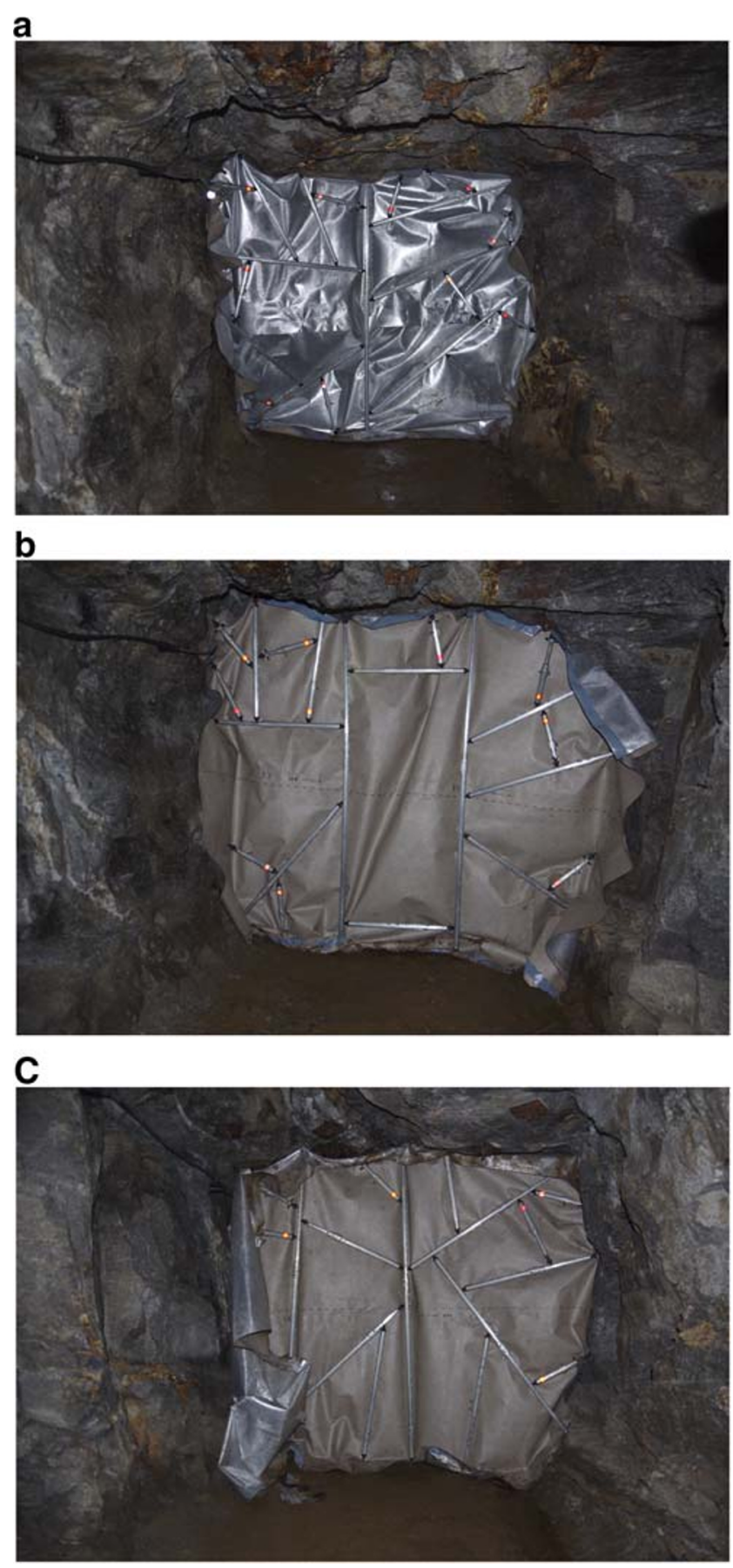

Fig. 15 Setup of the Quick-Erect Stopping System (QESS) by three troops of the Student Mine Rescue of the Technical University Bergakademie Freiberg in the gallery section Wilhelm Stehender in the Teaching and Research Mine Reiche Zeche with assembly times of $17 \mathrm{~min}$ (top), $11 \mathrm{~min}$ (middle), and $10 \mathrm{~min}$ (bottom)

galleries dating back centuries; they are water rich, cool with temperatures around $10{ }^{\circ} \mathrm{C}$ and display a high radon potential. No heavy mining machinery is used. Mine fires are not to be expected. Under these conditions, the QESS works well and protects miners from radon exposure. 


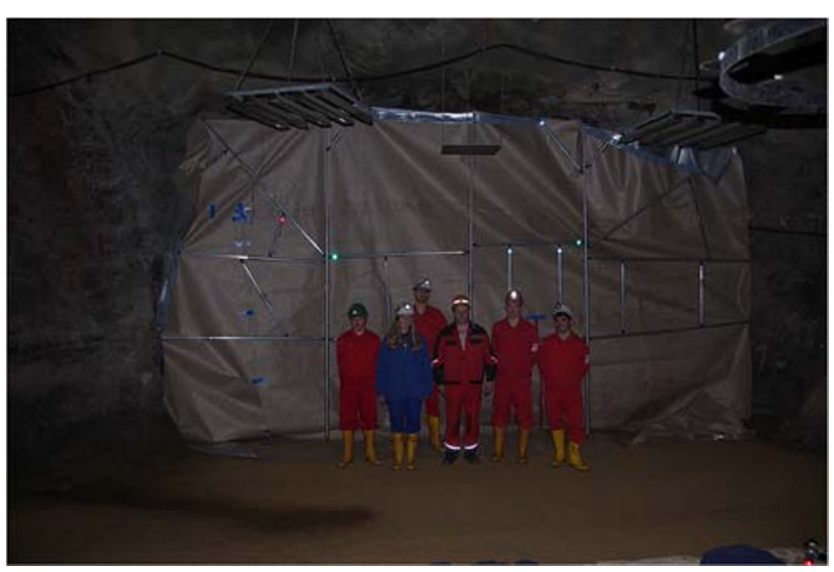

Fig. 16 Setup of the Quick-Erect Stopping System (QESS) in the show mine Zinnkammern in Pöhla

Costs are an important consideration of companies, when it comes to applying the QESS in Erzgebirge and Vogtland mountains. A complete system, including $50 \mathrm{~m}$ radon-proof foil, costs about $\$ 8000$. Single wall stoppings made of wood, foil, concrete, shotcrete, bricks, impregnated canvas, expanding polymer foams, or PVC are less expensive [12]. However, a simple cost comparison of QESS and other systems is misleading when based on one-time setup. The QESS is not designed to be cheaper than other systems. It is also not intended to replace systems that are built stationary for permanent use. The QESS was designed to protect miners from radon exposures very quickly due to its short assembly time. When using the QESS, radon protection is established faster than with other systems. The advantages of the QESS are all the greater, the shorter the service life of the stoppings and the more often a stopping has to be removed and rebuild again, for example in the event of blast operations. Miners are then able to evade many hours of work with radon exposures.

The QESS is reusable and comes with a $50 \mathrm{~m}$ long radontight foil for frequent assembly. When comparing the costs of QESS with other systems, its reusability needs to be taken into

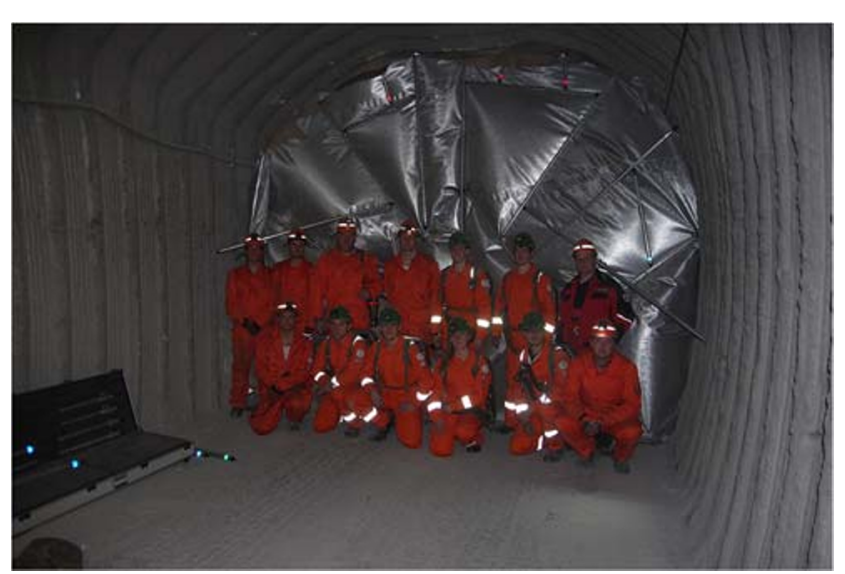

Fig. 17 Setup of the Quick-Erect Stopping System (QESS) in the salt mine Asse II in Remlingen account. Cost comparisons must also include the working hours of the miners and the cost for materials used.

Mull et al. calculated the construction costs for a small stopping of $1.5 \mathrm{~m}^{2}$ with five materials and three transportation distances for the year 2015 at the example of the "Reiche Zeche" mine in Freiberg, Germany [12]. At a manual transportation over distances of $500 \mathrm{~m}$, the costs are bluefield brattice cloth $250 €(\$ 270)$, timber $600 €(\$ 650)$, polyurethane 710 $€(\$ 770)$, concrete canvas CC5 $2170 €(\$ 2350)$, and concrete $5760 €(\$ 6230)$.

When building ten small stoppings of $1.5 \mathrm{~m}^{2}$, this will result in costs of $\$ 2700$ (bluefield brattice cloth), $\$ 6500$ (timber), $\$ 7700$ (polyurethane), $\$ 23,500$ (concrete canvas CC5), and $\$ 62,300$ (concrete).

The QESS costs $\$ 8000$. According to Mull et al., the working hour of a miner in 2015 was $57 €(\$ 62)$ in Germany including 50\% overhead [12]. The construction of a QESS with an area of $1.5 \mathrm{~m}^{2}$ takes $1 \mathrm{~h}$, including $500 \mathrm{~m}$ of transport distance. For two miners and ten-time assembly, this results in labor costs of $\$ 1240$. This means that a ten-time assembly of the QESS comes at a cost of $\$ 9240$. The cost is one third higher than the cost of wooden stoppings. With a 16-time assembly, the cost of the QESS (\$9984) is smaller than for wooden stoppings $(\$ 10,400)$.

The QESS is a new system. This article outlines the current state of development. Many questions about the application of QESS remain unanswered. A first technical, economic, and environmental assessment of the QESS in different mine settings comes from a study of Yildirim [1]. Further investigations must follow. This includes studies on the behavior of the materials of the QESS in case of a mine fire, on flammability, on the toxicity of gases, and on the recycling of foil and foam. Currently, it is also being investigated whether the QESS can be used for ceiling heights of up to $4 \mathrm{~m}$ (13 ft).

\section{Conclusion}

The QESS works well in small-scale mining. Using the QESS, mine openings of any shape can be sealed off in a short time. The QESS can protect miners from radon exposures. For mine rescue operations, the QESS can be used as ventilation predams to slow down fires and to protect against smoke and dust. The QESS has also proven useful in ventilation experiments.

Research to improve the QESS continues. It is particularly important that the QESS can be well-sealed with expanding foam, even at higher pressures in the galleries. In addition, the conditions for the safe use of the QESS will be investigated, especially with regard to pressure, temperature, fire, and the sizes of cross sections of galleries. 
Acknowledgments We would like to thank the students of the Student Mine Rescue of the Technical University Bergakademie Freiberg, and especially Lukas Manthey and Alfred Geers, for conducting three mine rescue drills with the QESS in the Teaching and Research Mine Reiche Zeche and the salt mine Schachtanlage Asse II in Remlingen, respectively. The drills led to valuable suggestions for improving the QESS. Furthermore, we would like to thank Tino Zupp, Michael Vater, and Andy Tauber of the Wismut Mine Rescue of Aue, Professor Jürgen Brune of the Colorado School of Mines, and the Front Range Mine Rescue of Idaho Springs, Colorado, for testing and giving feedback on the QESS. Open Access funding provided by Projekt DEAL.

\section{Compliance with Ethical Standards}

Conflict of Interest Jörg Dehnert holds a QESS patent. Jens Stopp is the owner of the Aluminiumbau und Verwaltungs GmbH Stopp, which produces the QESS. On behalf of all authors, the corresponding author states that there are no further conflicts of interest.

Open Access This article is licensed under a Creative Commons Attribution 4.0 International License, which permits use, sharing, adaptation, distribution and reproduction in any medium or format, as long as you give appropriate credit to the original author(s) and the source, provide a link to the Creative Commons licence, and indicate if changes were made. The images or other third party material in this article are included in the article's Creative Commons licence, unless indicated otherwise in a credit line to the material. If material is not included in the article's Creative Commons licence and your intended use is not permitted by statutory regulation or exceeds the permitted use, you will need to obtain permission directly from the copyright holder. To view a copy of this licence, visit http://creativecommons.org/licenses/by/4.0/.

\section{References}

1. Yildirim O (2019) New quick erect stopping system for underground mines: a technical, economic and environmental assessment of a newly developed ventilation and gas proof sealing system for the application in different mine settings.- Master-Thesis, Technical University Bergakademie Freiberg, Freiberg, Germany. https://doi. org/10.13140/RG.2.2.29388.97929/1

2. German Radiation Protection Act.- Federal Law Gazette, BGBl. I 2017, No 42 (in German)

3. Ordinance on the Protection against Damage and Injuries Caused by Ionizing Radiation (Radiation Protection Ordinance).- Federal Law Gazette, BGBl. I 2018, No 41 (in German)
4. Dehnert J (2017) Supervision of German miners at small underground construction sites of old mining to prevent high radon exposures. In: Clement C, Valentin J, Ogino H, Foote D, Reyjal J, Omar-Nazir L (eds) Proceedings of the 14th International Congress of the International Radiation Protection Association, Volume 2 of 5: 900-904

5. Dehnert J (2020) Radon exposures of miners at small underground construction sites in old mining: recommendations to improve radiation protection measures by the Saxon radiation protection authority. Health Phys 118(1):96-105

6. Dehnert J, Guhr A, Engelhardt J (2020) Improvement of a radon dosimetry system for miners by replacing reference dosimeters with radonproof boxes containing activated-carbon cartridges. Health Phys 118(2):117-128

7. Dehnert J, Stopp J, Schönherr B (2017) Express-WetterblendenSystem (EWS) - die wiederverwendbare Schnellbaublende für den Sofortschutz von Bergleuten unter Tage. In: Mischo H, Krichler T, Meyer L (eds) 3. Internationales Freiberger Fachkolloquium Baustoffe und Versatz.- Technische Universität Bergakademie Freiberg, ISBN 978-3-86012-5601, 142 p., 05.-06. October 2017, Freiberg, Germany: 135-138 (in German)

8. Dehnert J, Schönherr B, Stopp J (2016) Strahlenschutz im Altbergbau: Mobiles und wiederverwendbares ExpressWetterblenden-System zum Sofort-Schutz von Bergleuten vor Radonexpositionen. In: Busch W, Knospe St, Meier G, Sroka A, Löbel K-H, Klapperich H, Tondera D (eds) 16. AltbergbauKolloquium, ISBN 978-3-938390-18-4, 240 p., 10.-12. November 2016, Goslar, Germany: 173-181 (in German)

9. Dehnert J (2016) German patent DE 102016005 269, Verfahren zum Errichten einer Wetterblende und Wetterblende zur Durchführung des Verfahrens.- erteilt am 08.12.2016 (in German)

10. Medger U (2018) Strahlenschutz bei Bergsicherungsarbeiten im sächsischen Altbergbau.- Internship-Thesis, BA University of Cooperative Education Sachsen, Riesa, Germany, unpublished (in German)

11. Dehnert J, Schramm T, Stopp J (2017) Wetterversuch mit der Schnellbaublende Express-Wetterblenden-System (EWS) zur Dosisreduzierung bei Bergführern in einem Besucherbergwerk. In: Tzschentke C, Vahlbruch J-W (eds) Das neue Strahlenschutzrecht, Expositionssituationen und Entsorgung.Fachverband für Strahlenschutz e.V., 301 p., 9.-12. October 2017, Hannover, Germany: 245-249 (in German)

12. Mull A, Weyer J, Mischo H, Brune J (2016): Mine stopping construction and leakage.- SME Annual Meeting, Feb. 21-24, 2016, Phoenix, AZ, Preprint 16-150

Publisher's Note Springer Nature remains neutral with regard to jurisdictional claims in published maps and institutional affiliations. 